\title{
An uncaring state? The overrepresentation of First Nations children in the Canadian child welfare system
}

\author{
Brittany Barker BA, Gerald Taiaiake Alfred PhD, Thomas Kerr PhD
}

According to tradition, [children] are gifts from the spirit world and have to be treated very gently lest they become disillusioned with this world and return to a more congenial place. - Royal Commission on Aboriginal Peoples (1996)

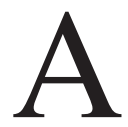
s the Idle No More movement fades in people's minds, concern remains that First Nations children continue to be left behind. In Canada today, Aboriginal youth represent about $5 \%$ of the youth population; however, nearly $50 \%$ of the children and youth under government care are of Aboriginal ancestry. ${ }^{1}$ In 2007, in response to ongoing disparities experienced by First Nations children receiving child welfare services, the First Nations Child \& Family Caring Society of Canada and the Assembly of First Nations launched a human rights complaint against the Government of Canada. The complaint alleges that by failing to provide equitable child welfare services and funding for children living on-reserve, Canada is discriminating against First Nations children and contributing to their continued overrepresentation in the child welfare system, with recent estimates suggesting that First Nations communities receive $22 \%$ less funding per child. ${ }^{2-4}$ In the context of this article, "First Nations" refers only to those who identify as "Indians" as defined by the Indian Act (i.e., this excludes Métis and Inuit people).

From the outset, Canada challenged the jurisdictional authority of the Canadian Human Rights Tribunal. This challenge was based on the arguments that comparing federally and provincially funded child welfare services is inappropriate and that the federal government is responsible only for allocating funds, not service provision, and therefore cannot be held liable for discrimination in service provision..$^{5}$ Ultimately, it was ruled that failing to provide equitable funding to on-reserve child welfare services constituted grounds for racial or ethnic discrimination and that the tribunal was the correct venue for adjudicating such allegations. Today, seven years later and after more than $\$ 3$ million has reportedly been spent on this case, the Government of Canada is still fighting the complaint before the tribunal. ${ }^{6}$

Youth exposed to the child welfare system are among society's most vulnerable citizens. A large body of scientific evidence has documented the elevated risk for homelessness, mental health issues, substance use, incarceration and unplanned pregnancies among those previously maltreated and subsequently exposed to the child welfare system. ${ }^{7}$ Exposure to child welfare refers to all youth and families who are investigated and monitored by the government for suspected maltreatment, whether or not subsequent out-of-home placement occurs. Aboriginal overrepresentation exists at every level of child welfare exposure (e.g., investigation, substantiated investigation, out-of-home placement) ${ }^{8}$ However, despite much research highlighting the harms that typically follow time spent in the child welfare system, policy-makers have failed to take action to address these outcomes among the children and youth they are obligated to protect.

Most government interventions involving Aboriginal families and out-of-home placements stem from charges of neglect rather than abuse. ${ }^{3,8}$ Structural and social factors such as poverty, inadequate housing, substance use and other vestiges of colonization continue to devas-

\section{- Ker pOINTS}

- Aboriginal youth comprise nearly $50 \%$ of the children under government care in many jurisdictions across the country.

- Since 2007, the First Nations Child \& Family Caring Society of Canada and the Assembly of First Nations have been embattled with the Government of Canada before the Human Rights Tribunal over inadequate funding for on-reserve child welfare.

- The health and social harms associated with exposure to the child welfare system are numerous, with elevated rates of substance use, homelessness, incarceration, underemployment and unplanned pregnancies.

- Physicians can play an important role in advocating for equitable levels of government funding and service provision. 
tate families and communities. Although many Canadians dismiss the idea that colonization still affects life in Canada today, the intergenerational trauma that resulted from the residential school era, including the loss of generations of familial support networks and parental rolemodelling, has been linked to the high number of neglect charges. ${ }^{3,9}$ As a consequence, it is estimated that three times as many First Nations children are under government care today than during the height of the residential school era. ${ }^{3}$ The last residential school closed in Saskatchewan in 1996, and the "Sixties Scoop," during which Aboriginal children were apprehended by child welfare services en masse and adopted to predominantly non-Aboriginal families, continued for nearly three decades. ${ }^{4}$

Canada's decentralized governance and split jurisdictions make reform of child welfare problematic. The Constitution of Canada assigns provincial and territorial governments control and responsibility over child welfare as well as funding for off-reserve programs, whereas the federal government is responsible for funding on-reserve programs. This results in inconsistent policies and practices, and fragmented data across the country, making it difficult to track trends and outcomes for children and youth exposed to the child welfare system. The split jurisdiction that applies to First Nations youth results in inequitable funding and a 2-tiered system of care. In 2008 and 2011, the Auditor General of Canada released reports admonishing Canada for failing to provide funding for preventive services, and for maintaining a funding formula (Directive 20-1) dating from 1988 that has not been updated to reflect legislative change, variation in child welfare services across provinces, the actual number of children in care or inflation. ${ }^{10}$

Aboriginal activists and agencies have repeatedly called for a paradigm shift from intervention to prevention; initiatives to accomplish this have produced mixed results. The Enhanced Prevention Focused Funding Approach replaced Directive 20-1; however, recent reviews of this model noted many of the same problems being replicated, particularly with respect to operational costs and the absence of measures to compare federal and provincial funding. ${ }^{4,10}$ Establishment of a national steering committee tasked with monitoring national trends for both Aboriginal and non-Aboriginal youth exposed to the child welfare system would allow researchers and policy-makers to more effectively identify areas where intervention is needed. Comprehensive and longitudinal research to identify the factors driving the high prevalence of neglect charges among Aboriginal families (e.g., programs targeting poverty, inadequate housing, substance misuse) is needed. Such research should be undertaken in collaboration with affected communities. Aboriginal researchers have called for service programming and delivery cultivated by Aboriginal people as key to successful programming. ${ }^{3}$

Physicians can do much to improve the lives of Aboriginal families and youth exposed to the child welfare system. This can include helping all Canadians, including policy-makers, better understand the legacy of colonization, as well as the health and social effects of intergenerational trauma. Physicians can also play an important role in advocating for system-level changes to better address the challenges faced by youth and families exposed to child welfare services, including advocating for equitable levels of government funding and service provision. Physician training opportunities within Aboriginal communities, collaborative work with community health representatives, and the development of cross-cultural communication skills among physicians are also needed. ${ }^{11}$ Multiple reports have identified the inadequate numbers of Aboriginal health care professionals. ${ }^{11,12}$ Accordingly, efforts are needed to strengthen the capacity of Aboriginal professional organizations (e.g., Indigenous Physicians Association of Canada) to provide mentorship and improve recruitment, training and retention of Aboriginal health care providers.

\section{References}

1. 2011 national household survey: Aboriginal peoples in Canada: First Nations people, Métis and Inuit. Ottawa (ON): Statistics Canada; 2011. Cat. no. 11-001-X. Available: www.statcan.gc.ca/daily -quotidien/130508/dq130508a-eng.htm (accessed 2013 Aug. 1).

2. McDonald R-A, Ladd P. First Nations Child and Family Services: joint national policy review. Ottawa (ON): Assembly of First Nations/Department of Indian and Northern Affairs Development; 2000.

3. Blackstock C, Trocmé N. Community-based child welfare for Aboriginal children: supporting resilience through structural change. Soc Policy J NZ 2005;24:12-33.

4. Sinha V, Trocmé N, Fallon B, et al. Kiskisik Awasisak: remember the children. Understanding the overrepresentation of First Nations children in the child welfare system. Ottawa $(\mathrm{ON})$ : Assembly of First Nations; 2011. Available: www.fncaringsociety.com/sites/ default/files/docs/FNCIS-2008-report.pdf (accessed 2013 Aug. 1).

5. Canadian Human Rights Commission v. Canada [2012]. 2012 FC 445. Available: www.fncaringsociety.ca/sites/default/files/fnwitness /T-578-11\%20Order\%20English $\% 20 \% 28$ April $\% 2018 \% 2 \mathrm{C} \% 20$ 2012\%29.pdf (accessed 2013 Aug. 1).

6. Scoffield H. Ottawa spends \$3-million to battle First Nations child welfare case. The Globe and Mail [Toronto] 2012 Oct. 1. Available: www.theglobeandmail.com/news/national/ottawa -spends-3-million-to-battle-first-nations-child-welfare-case/article 4581093/ (accessed 2013 Dec. 7).

7. Courtney ME, Piliavin I, Grogan-Kaylor A, et al. Foster youth transitions to adulthood: a longitudinal view of youth leaving care. Child Welfare 2001;80:685-717.

8. Sinha V, Trocmé N, Fallon B, et al. Understanding the investigation-stage overrepresentation of First Nations children in the child welfare system: an analysis of the First Nations component of the Canadian Incidence Study of Reported Child Abuse and Neglect 2008. Child Abuse Negl 2013;37:821-31.

9. Kirmayer L, Valaskakis GG. Healing traditions: the mental 
health of Aboriginal peoples in Canada. Vancouver (BC): University of British Columbia Press; 2009.

10. 2011 June status report of the Auditor General of Canada. Ottawa (ON): Office of the Auditor General of Canada; 2011. Available: www.oag-bvg.gc.ca/internet/English/parl_oag_201106_04_e _35372.html\#hd3b (accessed 2014 Feb. 10).

11. CMA policy: The health of Aboriginal peoples 2002. Ottawa (ON) Canadian Medical Association; 2002. Available: http://policybase .cma.ca/dbtw-wpd/PolicyPDF/PD03-02.pdf (accessed 2014 Feb. $10)$.

12. Macaulay AC. Improving Aboriginal health: How can health care professionals contribute? Can Fam Physician 2009;55:334-9.
Affiliations: British Columbia Centre for Excellence in HIV/AIDS, St. Paul's Hospital (Barker, Kerr), Vancouver, BC; School of Public Policy (Barker), Simon Fraser University, Vancouver, BC; Indigenous Governance (Alfred), University of Victoria, Victoria, BC; Department of Medicine, Faculty of Medicine (Kerr), University of British Columbia, Vancouver, BC

Contributors: All of the authors contributed to drafting and revising the article, and approved the final version submitted for publication. 